toxicity. (5) Boiling with a .2 per cent. aqueous solution of hydrochloric acid has but little, if any, effect upon the germ cell or its contained toxin. (6) Heating the germ substance for an hour at the temperature of the water-bath with water containing from one to five per cent. of hydrochloric acid lessens but does not destroy the toxicity of the cell. (7) The toxin may be partially separated from the cell wall by digestion of the whole with hydrochloric acid and pepsin. (8) With the dried bacterial cells rabbits may be immunized to the colon bacillus. (9) Rabbits thus immunized furnish an antitoxic serum. This antitoxic serum agglutinates the colon bacillus and precipitates the toxin from suspensions in water.

H. W. CONN.

WESLEYAN UNIVERSITY.

\section{THE NEW VAPOR-ENGINES.}

THE recent announcement from Berlin of the successful construction of a new ' binary-vapor,' or, as the writer has been accustomed to designate it, 'series-vapor engine,' and the almost simultaneous account in the Paris technical and scientific journals of a 'newly invented' ether-vapor engine, are reviving an old-time error. The distinction between the latter of the two systems and the former, between a fallacy and known truth, as fundamental elements of the revival of these classes of heat-engine, is once more a subject of misconception with the technical and even, often, with the scientific writers describing them.

Professor Josse, at the great Charlottenburg technical school, and his co-workers among the steam-engine builders of Berlin, have been for some time at work determining the practicability of utilizing the binary-vapor 'system of heat-engine, supplementing the steam-engine by a 'wasteheat engine' in which a more volatile vapor is employed to transform into useful mechanical energy the large fraction of heat rejected from the former. ${ }^{*}$ The system is old; well-known and entirely correct, thermodynamically.

The real question of the moment which is sought to be solved is the practical one: With our refined systems of design, construction and manipulation, to-day, is it possible to practically, safely and conveniently and, above all, economically employ this system, often previously tried and found wanting, and to thus secure, for the user, a larger return of power for the unit of expenditure and for the life of the 'plant' than by use of the steam-engine alone? Can dividends be increased through an unquestionably greatly improved thermodynamic transformation of energy?

There is here no question of thermodynamics or of a possibility of dynamic gain; the experiment has often been tried and this possibility exhibited beyond question. It is now a matter of choice of secondary fluid, of safety, permanence of construction, convenience, reliability, ultimate gain in returns on the investment and operative costs. It is now thought, by those most familiar with the facts of this new case, that this problem has at last been solved and that the 'series-vapor engine' will find a permanent place in the arts. Time and experience will confirm or refute their conclusions.

Susini, in Paris, on the other hand, has introduced a 'new' vapor-engine in which he substitutes ether for steam, maintaining that the machine is advantageous as a primary rather than as a secondary or wasteheat engine, and, if his reporters are correct, basing his claim to this superiority upon the assertion that ether, with its volatility and low latent heat of vaporiza-

* Mittheilungen aus dem Maschinen-Laboratorium der Kgl. Techn. Hochschule zu Berlin, 1901 . 
tion has thus great intrinsic advantage over the vapor of water as a working fluid in the heat-engine. This is a well-known and oft-repeated fallacy, and it has been almost as common among inventors or would-be inventors as was formerly, according to Dircks, that of a 'perpetuum mobile.'

The thermodynamic efficiency of any heat-engine is determined, at best, by the range of temperature worked through and without regard to the nature of its working substance. It is true that the practicability of employment of one or another fluid in the heat-engine varies with the temperature- and pressure-ranges and that there is as yet no known fluid which precisely adapts itself to the demand of the engineer within the practical limits of pressure and of temperature, coincidently, which he now safely, conveniently and economically handles. He finds one fluid suited to the pressure, the other to the temperature-range, one to the upper, another to the lower, portion of either scale; but he knows of none which meets his needs on both scales.

The proposition regarding 'latent' heats is easily verified by reference to the wellknown expression of Rankine for the work, $U_{1}$, of the common vapor-engine cycle with complete, adiabatic, expansion between $T_{1}$ and $T_{2}$, and without compression :*

$$
\begin{aligned}
U_{1} & =\int_{p_{2}}^{p_{1}} u d p=\int_{T_{2}}^{T_{1}}\left(J C \log _{\mathrm{e}} T_{1} / T_{2}+v_{1} d p_{1} / d T_{1}\right) d T ; \\
& =J C\left[T_{1}-T_{2}\left(1+\log _{\mathrm{e}} T_{1} / T_{2}\right)\right]+H_{1}\left(T_{1}-T_{2}\right) / T_{1} ;
\end{aligned}
$$

where $H_{1}$ is the 'latent' heat of vaporization at $T_{1}$ in dynamic units.

The work of compression in the Carnot cycle, to which this cycle is reduced by its introduction, is found by making $H_{1}=0$, the compression reducing the fluid to the

\footnotetext{
* 'Manual of the Steam-Engine,' p. 387.
}

liquid state at the close of the compression period, when we shall have

$$
U_{2}=\int_{p_{2}}^{p_{1}} u d p=J C\left[T_{1}-T_{2}\left(1+\log _{e} T_{1} / T_{2}\right)\right] .
$$

Deducting this quantity, the first expression reduces to that for the work of the Carnot cycle for vapors,

$$
U_{1}-U_{2}=H_{1}\left(T_{1}-T_{2}\right) / T_{1} ;
$$

which is identical with that for gases when, for $H_{1}$, the latent heat of vaporization, is substituted the latent heat of isothermal expansion at $T^{1}$.* $^{*}$

In other words, in the 'perfect-engine cycle' of Carnot, whether for one or another working fluid, or even for solids serving as working substances, the work is all performed by 'latent' heat; while, in the common steam-engine or other vapor-engine cycle, it is obtained from 'latent' heat more and more completely as the cycle approximates more and more closely to the conditions of maximum efficiency.

It is further evident from the above that efficiency is independent of the magnitude of the value of $H$, in the Carnot cycle, as well as of the measure of $J$ or of $C$, the specific heat. As Carnot himself announced in 1824, maximum efficiency is not dependent upon the nature of the working fluid, and one vapor is as good as another in this respect. The magnitude of $H$ determines how much heat shall be stored in the working substance in each cycle and how many units of weight of that fluid will be required per unit of work performed. Thus, with steam, a smaller number of pounds per horse-power-hour are required, other things equal, than with ether, or, in fact, with any other known substance; although the number of thermal units per unit of work developed in the

\footnotetext{
* Thurston's 'Manual of the Steam-Engine,' Vol. I., p. 796.
} 
unit of time will be the same for all. Efficiency remains the same while the quantity of working fluid circulating will vary inversely as the quantity of its 'latent' heat of vaporization.

In the actual engine, conditions external to the cycle determine the relative desirability of available fluids and extra-thermodynamic circumstances control. Since the machine has weight and is subject to friction; since the material of which it is composed is always a good conductor of heat; since the cost of production of power and that of purchase of machinery is a controlling factor; these and other, minor, conditions affecting the problem of the real engine compel the engineer to seek a working fluid that shall best combine minimum cost of fluid and of mechanism, maximum heat-storing power, maximum 'mean effective pressures' and minimum liability to heat-wastes other than thermodynamic. $\mathrm{He}$ is limited by pressures difficult to control safely and permanently in the steamengine, by temperatures beyond his range of satisfactory operation in the gas-engine and by costs and risks, often very serious, with other fluids; while he finds it impracticable to utilize the lower portion of the temperature-range in the steam-engine and, in vastly greater degree, finds a similar limitation in the standard gas-engine.

No known fluid, up to this time, at least, has been found to satisfactorily combine the manageable range of temperature with the safe range of pressure in the heat-engines so as to serve as the ideal working substance. On the whole, steam has proved thus far best.

By combining fluids in series, however, it is at least ideally possible to secure this coincidence of available pressure- and temperature-ranges. 'Thus, it has often been proposed to utilize the rejected heat of the gas-engine in an accessory steam-engine, to thermodynamically transform the waste- heat of the latter by a secondary apparatus: employing one of the more volatile liquids. in a cycle of low temperature-range. Wellington attempted to find a series of fluids, to be worked in a number of engines in series in this manner, years ago, and every aspect of the case has been carefully studied, and usually more or less thoroughly investigated experimentally by engineers, physicists and inventors.

Nothing new in this branch of the subject has been discovered recently. It is, however, usually the fact that the earlier inventors have commonly reported a measurable gain by the substitution of the more volatile substance for steam in heatengines. It has seldom been large; but has. been sufficient to make it evident to engineers that the problem involved is not to be absolutely ignored. It seems probable that most of these available fluids possess some advantage in one if not both of two ways. -higher mean effective pressures at low ranges of cycle temperatures and less freedom of heat-exchange with the metal of the cylinder.* As the former permits expansion to a lower limit of temperature, as the gain by extending the range downward is comparatively large and as wastes by internal heat-exchanges are usually serious, in the common forms of engine, the engineer is interested in watching developments in the use of other fluids than steam, though not as yet expecting much progress through their use in the simple engine.

-With the 'waste-heat engine' of the 'binary-vapor system' the case is different. There exists a very large defect in the standard steam-engine in its inability to utilize the temperature-range of its cycle below about $50^{\circ} \mathrm{C}$. $\left(122^{\circ} \mathrm{F}\right.$.), while it is usually true that at least one half, and often much more than one half, of the heat-

\footnotetext{
* Thurston's 'Manual,' Vol. I., pp. 172-704, 911-921.
} 
energy which should be transformed into work escapes transformation simply because of the low terminal pressures of the engine at the lowest temperatures of its range. It is this loss which is sought to be reduced by the series-fluid engines and which, so far as the thermodynamic and the dynamic questions are concerned, may be actually saved in large degree. The uncertainty remaining is that regarding costs, safety and convenience.

Du Trembley, about two generations ago, built binary-vapor engines, with ether as the secondary fluid, for a line of transoceanic steamers and 'broke the world's records' for his time in economy of powerproduction; but the compound engine came in and his secondary fluid proved dangerously inflammable. He lost one of his ships, Randolph \& Elder bettered his record and the matter dropped out of sight. Later, many inventors have gone through the same experience in one way or another. Ether, chloroform, alcohol, ammonia, carbon-disulphide and sulphur-dioxide, among other volatile substances, have been tried, usually with some apparent gain but never yet with permanent success.

Recently, however, Professor Josse, at Berlin, has again 'broken the world's record' in heat-engine operation by producing the horse-power with an expenditure of less than eight and a half pounds of moderately superheated steam per hour. The experiment has been made with the utmost care and repeated under varying conditions, until there can remain no doubt of the fact. He further states that the steam and sulphur-dioxide, binary-vapor system adopted by him can be constructed at no greater cost than the standard tripleexpansion engine which it rivals, that, properly cared for, it is not subject to injury by corrosion as had been anticipated by engineers generally, and that it can be safely insured against loss or accident through leakage. If experience confirms this claim, this means that the long-sought utilization of the waste heat of the steamengine may be practically accomplished.

Time and experience will confirm or refute these expectations and it is for time and experience to settle the ultimate questions of the engineer relative to cost, reliability, safety and net gain or loss by the substitution of the series-vapor engine for the compound, the single-fluid, seriesengine.

R. H. Thurston.

\section{WHAT ARE THE REQUIREMENTS OF A COURSE TO TRAIN MEN FOR WORK IN TECHNICAL CHEMISTRY.*}

THE subject before us may be discussed in two parts ; first, what sort of instruction in chemistry should be given to men who are to become technical chemists, and, second, what work in other subjects should be required? Our consideration of the question will perhaps be more definite if we have before us a list of the occupations followed by a number of young men who have received training of this sort.

During the past twelve years twentythree men have graduated from the chemical course of the Rose Polytechnic Institute. These have been employed as follows: One is inspector of coke for a large steel company, three are chemists in iron or steel laboratories, two are assayers, two are teachers, three chemists in soap factories, two employed by a firm manufacturing liquid carbon dioxide, two are draftsmen, one is superintendent of a gas company, one chemist for a firm manufacturing photographic supplies, one chemist for a paint oil company, one chemist for an electrical company, one manager of the paint department for a wholesale

* Read at the meeting of the Indiana College Association, December 27, 1901, and also at the Philadelphia meeting of the American Chemical Society. 